\title{
Metales pesados (Cd, Cr y Hg): su impacto en el ambiente y posibles estrategias biotecnológicas para su remediación
}

Heavy metals (Cd, $\mathrm{Cr}$ and $\mathrm{Hg}$ ): impact on environment and possible biotechnological strategies for remediation

\section{MAYRA ELEONORA BELTRÁN PINEDA}

Biólogo

MSc. Ciencias Microbiología Grupo de Investigación Gestión Ambiental

Universidad de Boyacá, Colombia mebeltrán@uniboyaca.edu.co

\section{ALIDA MARCELA GÓMEZ RODRIGUEZ}

Biólogo

MSc. Ciencias Biológicas Grupo de Investigación NÚCLEO Universidad de Boyacá, Colombia aligomez@uniboyaca.edu.co 


\title{
RESUMEN
}

Los metales pesados son un grupo de elementos químicos que están presentes en la naturaleza haciendo parte de la corteza terrestre en pequeñas cantidades; sin embargo, debido a diversas actividades antrópicas de tipo industrial y agrícola, su concentración se ha incrementado significativamente en diversos tipos de ecosistemas. Se han reportado impactos ambientales graves y debido a su toxicidad han ocasionado problemas de salud en las comunidades presentes en las áreas de influencia. Se requiere de la implementación de tecnologías ambientalmente sostenibles con el fin de realizar un tratamiento viable que logre disminuir considerablemente la carga contaminante a causa de metales pesados. Actualmente se están estudiando e implementando tecnologías que involucran el uso de microorganismos tolerantes o resistentes y plantas hiperacumuladoras de metales pesados en ensayos a nivel in vitro y en campo con resultados promisorios. El objetivo de la presente revisión es conocer qué son los metales pesados, el impacto ambiental que generan, sus propiedades tóxicas que son la causa de muchas patologías humanas y las posibles biotecnologías que existen actualmente para su remediación.

Palabras clave: Biotecnología, contaminación, microorganismos tolerantes y resistentes a metales, plantas hiperacumuladoras, toxicidad.

\begin{abstract}
Heavy metals are a group of chemical elements that are present in nature making part of the Earth's crust in small amounts, however due to various human activities of industrial and agricultural type, its concentration increased significantly in different ecosystems. Serious environmental impacts have been reported and due to its toxicity, the heavy metals have caused health problems in communities present in the areas of influence. The implementation of environmentally sustainable technologies is required in order to make a viable treatment that will considerably reduce the pollutant load caused by heavy metals. Currently, technologies that involve the use of tolerant or resistant microorganisms and plants hyperaccumulating heavy metals in vitro and in the field are studying and implementing with promising results. The aim of this review is to know what heavy metals are; the environmental impact they may generate their toxic properties which are the cause of many human diseases and potential biotechnologies that currently exist for its remediation.
\end{abstract}

Keywords: biotechnology, pollution, metal tolerant and resistant microorganisms, hyperaccumulating plants, toxicity. 


\section{INTRODUCCIÓN}

La liberación de contaminantes al medio ambiente debido a las actividades antrópicas se ha incrementado enormemente; la producción a gran escala de compuestos químicos tales como solventes orgánicos, combustibles y sus aditivos, pesticidas, pigmentos, pinturas, plásticos y materias primas de origen químico ha causado el deterioro de la calidad ambiental (Garbisu et al., 2003). Otras actividades contaminantes incluyen prácticas agrícolas o industriales como la producción de estaño y otras aleaciones, galvanización de hierro, confección de baterías, industria minera y lixiviación de depósitos naturales (Marrero-Coto et al., 2010).

A nivel mundial se ha incrementado la contaminación por metales pesados generando perjuicios a la salud y el ambiente, para el año 2005 los países europeos presentaron cerca de 1.7 millones de hectáreas (ha.) afectadas, en Estados Unidos 1 millón de ha. de tierras agrícolas, 55.000 ha de pastos y 50.000 ha. de bosques son los más degradados por este tipo de contaminación; y en otros países como China, India, Pakistán y Bangladesh la contaminación por metales en el agua y el suelo es severa debido a que los efluentes de algunas industrias no son tratados correctamente (Ragnarsdottir y Hawkins, 2005).

En Colombia, una de las problemáticas ambientales más importantes se refiere al uso de metales pesados en sectores productivos minero, energético, agrícola e industrial (Rudas et al, 2013). Lo anterior, ha llevado a que la contaminación química por metales pesados, constituya una de las más peligrosas amenazas para los ecosistemas acuáticos y las especies presentes. Sin embargo, es escaso el conocimiento que se tiene en el país acerca de la problemática generada por la disposición de metales pesados en los cuerpos de agua, su impacto sobre el recurso hídrico, el deterioro de ecosistemas y la salud humana.

Estudios realizados sobre concentraciones de mercurio y otros metales pesados en peces dulceacuícolas del río Magdalena por Mancera y Álvarez (2006), indican que estos organismos tienen la capacidad de almacenar una concentración mayor de estos compuestos en comparación con la presente en el medio, por lo que son un indicador importante de la contaminación; esto implica que su consumo se puede convertir en un problema de salud para las poblaciones que se alimentan de este recurso.

Así mismo, Noreña en el año 2012 identificó altas concentraciones de $\mathrm{Cd}$ y $\mathrm{Cr}$ en la calidad del agua del río Magdalena, principal vía fluvial de Colombia, indicando que especies de peces representativos de esa zona, han sido gravemente afectados por el uso de metales pesados en actividades antropogénicas. Otras investigaciones realizadas en la ciénaga grande de Santa Marta evaluaron la distribución 
vertical de metales pesados $\mathrm{Pb}, \mathrm{Cd}$ y $\mathrm{Zn}$ en el sedimento asociado a las plantas de Rhizophora mangle y determinaron que la acumulación de metales principalmente en formas no biodisponibles, lo cual indica que la mayor parte de estos elementos se encuentran retenidos en el sedimento y podrían ser potencialmente movilizados por cambios del potencial redox (Parra y Espinosa, 2010; Espinosa et al., 2011).

En ecosistemas terrestres, el suelo es el principal depósito de contaminantes químicos, igualmente en ecosistemas acuáticos, los sedimentos funcionan como repositorio de estos compuestos (Bolán et al., 2004). Estos contaminantes varían en su composición y concentración, entran al sistema como resultado de un amplio rango de acciones como aplicaciones intencionales, inadecuada disposición de residuos, derrames accidentales o uso inapropiado. Metales como cadmio, plomo, cobalto, cobre y zinc se encuentran frecuentemente en el suelo y en altas concentraciones (Nessner et al., 2010).

Muchos metales pesados son indestructibles y representan una amenaza ya que no pueden ser degradados ni química, ni biológicamente, es decir no son biodegradables, algunos de estos metales pueden concentrarse a lo largo de la cadena alimenticia y eventualmente bioacumularse en el cuerpo humano (Wu et al., 2010). Es imperativo desarrollar tecnologías innovadoras como las estrategias de biorremediación, las cuales puedan remediar económicamente desechos tóxicos que impactan negativamente al medio ambiente (Garbisu et al., 2003).

Solo algunas especies de microorganismos y plantas que portan sistemas genéticos especializados logran contrarrestar los efectos tóxicos de los metales y son capaces de sobrevivir en ambientes con elevadas concentraciones de estos elementos (Wu et al., 2010; Marrero-Coto et al., 2010), gracias a esta capacidad se han podido diseñar biosensores para el control o seguimiento de la concentración de metales pesados en una gran variedad de sustratos, se han desarrollado procesos de biorremediación que incluyen el diseño de biorreactores para extraer o eliminar metales pesados desde efluentes contaminados o suelos y se han implementado procesos de bioaumentación y fitoremediación con buenos resultados a la hora de mitigar el efecto negativo de estas sustancias (Marrero-Coto et al., 2010). El objetivo de este artículo es dar a conocer qué son los metales pesados, sus propiedades fisicoquímicas y tóxicas, además de algunas estrategias biotecnológicas para su remediación.

\section{PROPIEDADES FISICOQUÍMICAS DE LOS METALES PESADOS}

Un metal pesado se define como un elemento que tiene propiedades metálicas como ductibilidad, conductividad, densidad, estabilidad como catión y especificidad a ligando (Garbisu et al., 2003). Bajo la denominación de metales pesados se incluye a un conjunto de 65 elementos de la tabla periódica con un número atómico mayor a 20 y con una alta densidad relativa mayor o igual a $5 \mathrm{~g} / \mathrm{cm}^{3}$ en su forma elemental. Estos presentan diferentes características fisicoquímicas y biológicas, se encuentran formando complejos como iones libres o participando en reacciones redox que resultan potencialmente tóxicas 
para los organismos (Duffus, 2002; Lucho et al., 2005; Marrero-Coto et al., 2010). En la tabla 1 se presentan los diferentes orígenes de algunos metales pesados.

\begin{tabular}{|c|c|}
\hline METAL PESADO & FUENTE/ORIGEN \\
\hline Cromo & Industria de electroplatino, lodos, residuos sólidos, curtiembres. \\
\hline Cadmio & $\begin{array}{c}\text { Orígenes geogénicos actividades antropogénicas, fundición y refinación de metales, } \\
\text { quema de combustibles fósiles, aplicación de fertilizantes fosforados, aguas residuales } \\
\text { y lodos. }\end{array}$ \\
\hline Mercurio & $\begin{array}{l}\text { Erupciones volcánicas, incendios forestales, emisiones de industrias productoras de } \\
\text { soda caústica, quema de madera, carbón y turba. }\end{array}$ \\
\hline Arsénico & $\begin{array}{l}\text { Semiconductores, preservantes de madera, aditivos de alimentos para animales, herbi- } \\
\text { cidas, volcanes, minería y fundición. }\end{array}$ \\
\hline Cobre & Industria de electroplata, minería y fundición, biosólidos. \\
\hline Plomo & Minería y fundición, quema de gasolina, residuos municipales, industriales, pinturas. \\
\hline Selenio & $\begin{array}{l}\text { Minería de carbón, refinación de aceites, combustión de combustibles fósiles, industria } \\
\text { manufacturera de vidrio y síntesis química. }\end{array}$ \\
\hline Zinc & Industria de electroplata, minería y fundición y biosólidos. \\
\hline
\end{tabular}

Tabla 1. Orígenes de algunos de los metales pesados.

Fuente: Lone et al., 2008 modificado por los autores.

Los metales pesados se clasifican en tres clases de acuerdo a sus funciones y efectos biológicos: 1) metales esenciales con funciones biológicas conocidas que son requeridos en cantidades traza como nutrientes para la vida de los organismos ( $\mathrm{Na}, \mathrm{K}, \mathrm{Mg}, \mathrm{Ca}, \mathrm{V}, \mathrm{Mn}, \mathrm{Fe}, \mathrm{Co}, \mathrm{Ni}, \mathrm{Cu}, \mathrm{Zn}, \mathrm{Mo} \mathrm{y} \mathrm{W}$ ); 2) metales tóxicos, los cuales pueden ejercer un efecto nocivo aún en bajas concentraciones (Ag, Cd, Cr, Sn, Au, $\mathrm{Hg}, \mathrm{Ti}, \mathrm{Pb}, \mathrm{Al}$ y metaloides $\mathrm{Ge}, \mathrm{As}, \mathrm{Sb}$ y Se) y 3) los metales no esenciales, que no son tóxicos y sus efectos biológicos son desconocidos (Rb, Cs y Sr) (Roane y Pepper, 2000; Lucho et al., 2005).

Los metales pesados se encuentran generalmente como componentes naturales de la corteza terrestre, en forma de minerales, sales u otros compuestos (Abollino et al., 2002); algunos metales pesados son requeridos como micronutrientes para las plantas (Van Assche et al., 1990 ), ciertos metales de transición son esenciales para algunos procesos celulares, ya que ejercen funciones catalíticas en determinadas reacciones bioquímicas o en conversiones metabólicas, actúan como micronutrientes o cofactores enzimáticos y pueden estabilizar estructuras proteicas, facilitar el transporte de nutrientes y la neutralización y control de la presión osmótica (Bruins et al., 2000; Rajendran et al., 2003). Sin embargo, a concentraciones superiores ejercen un marcado efecto citotóxico por lo que el mantenimiento de las 
concentraciones adecuadas es un factor importante para lograr la homeóstasis celular (Marrero-Coto et al., 2010).

Por otra parte, los metales pesados están presentes en suelos y corrientes acuáticas como componentes naturales o como resultado de la actividad humana en procesos como minería, fundición de metales, galvanoplastia, producción de energía y combustibles, vertido de lodos y agricultura intensiva (Garbisu et al., 2003). Así mismo, las formas geoquímicas de los metales en los suelos afectan su solubilidad, lo cual se relaciona directamente con su biodisponibilidad; el destino de los metales pesados en el suelo depende principalmente de la forma química del metal pero también de las condiciones ambientales y edáficas como el pH, potencial redox y contenido de materia orgánica (Rajendran et al., 2003).

La capacidad de intercambio catiónico (CIC) afecta la biodisponibilidad del metal y depende del contenido de materia orgánica y arcillas del suelo; la toxicidad de los metales en suelos con alta CIC es baja, mientras que en suelos con baja CIC la toxicidad aumenta (Roane et al., 2000). A pH ácidos la biodisponibilidad del metal aumenta debido a formas iónicas libres, pero a pH básicos la biodisponibilidad disminuye debido a la formación de minerales de fosfatos y carbonatos insolubles (Rajendran et al., 2003).

Los metales son las únicas sustancias que no pueden ser degradadas biológica ni químicamente, solo pueden ser modificadas o transformadas de un estado de oxidación a otro o de un complejo orgánico a otro (Abollino et al., 2002; Bolán et al., 2014). Como consecuencia de la alteración de los estados de oxidación pueden transformarse en sustancias más solubles en agua que pueden eliminarse por lixiviación; otros se convierten a formas menos solubles lo que conduce a su precipitación haciéndose menos disponibles; y otros pueden transformarse en sustancias menos tóxicas volátiles que pueden ser removidas del área contaminada (Garbisu y Alkorta, 1997).

\section{PROPIEDADES TÓXICAS DE LOS METALES PESADOS (Cr, Cd, Hg)}

La mayoría de los metales pesados son el origen de la contaminación ambiental (Solicio et al., 2007). Estos alcanzan el ambiente edáfico a través de procesos antropogénicos y pedogénicos; muchos metales pesados están presentes de forma natural en el suelo haciendo parte de materiales parentales como rocas ígneas, rocas sedimentarias y carbón; también aparecen en la naturaleza debido al desgaste de dicho material (Bolán et al., 2004); sin embargo, su concentración final no rebasa los umbrales de toxicidad y se encuentran bajo formas que son poco asimilables para los organismos (Marrero-Coto et al., 2010). 
A diferencia de las entradas por procesos pedogénicos, los metales pesados que son adicionados por actividades antropogénicas típicamente tienen mayor biodisponibilidad (Lamb et al., 2009). La entrada de metales pesados al suelo permite que ingresen a la cadena alimenticia, pero esto depende de la cantidad y origen del metal, las propiedades del suelo, la tasa y magnitud de toma por parte de las plantas y la absorción por parte de animales (Bolan et al., 2014). Para que los metales puedan ejercer su toxicidad, estos deben encontrarse disponibles para ser captados por los seres vivos, es decir biodisponibles (Soto et al., 2010).

Las actividades industriales generan la movilización de metales pesados y producen serias repercusiones en el ecosistema, de esta manera altas concentraciones de los metales pesados pueden generar afectaciones serias en la salud de los humanos y otras formas de vida como animales y plantas (Duffus, 2002). Es conocido que las altas concentraciones de metales pesados pueden afectar la microbiota de ecosistemas directamente a través de la modificación del tamaño de la población, la diversidad y la actividad (Rajapaksha et al., 2004). Cambios en el perfil de elementos traza del suelo producen alteraciones fisiológicas y genéticas en varias formas de vida como plantas, fauna acuática, insectos, anélidos, aves y mamíferos (Rajendran et al., 2003).

Los metales pesados tóxicos como cromo $\mathrm{Cr}, \mathrm{Hg}$ y $\mathrm{Cd}$ en el ambiente generan serios problemas en la calidad del agua y en la salud humana. Estos iones generan interferencias en las funciones metabólicas y en procesos bioquímicos y fisiológicos como la respiración y en la degeneración en la mayoría de los organelos celulares, incluso puede producir muerte celular. Recientemente altas concentraciones de metales pesados tales como cadmio, cromo y mercurio en suelos han sido reportadas en varios países y se han asociado con defectos de nacimiento, cáncer, lesiones de piel, retraso que conlleva a discapacidad, daño en hígado o riñón y otras enfermedades (Rajendran et al., 2003).

La tabla 2 resume los principales efectos de algunos metales pesados como cadmio, cromo y mercurio sobre las plantas, animales y seres humanos. 


\begin{tabular}{|c|c|c|}
\hline METAL & EFECTO SOBRE LAS PLANTAS & $\begin{array}{c}\text { EFECTO SOBRE LOS ANIMALES Y } \\
\text { SERES HUMANOS }\end{array}$ \\
\hline Cadmio & $\begin{array}{l}\text { Disminución de la tasa de ger- } \\
\text { minación de semillas, contenido } \\
\text { de lípidos y crecimiento gene- } \\
\text { ral de las plantas. Induce la pro- } \\
\text { ducción de fitoquelatinas. } \\
\text { - Interferencia en el estableci- } \\
\text { miento de la simbiosis entre } \\
\text { microorganismos y plantas. } \\
\text { - Incremento en la predisposi- } \\
\text { ción de las plantas a la invasión } \\
\text { por hongos. }\end{array}$ & $\begin{array}{l}\text { - Afectaciones gastrointestinales, respirato- } \\
\text { rias y efectos nocivos a nivel de órganos } \\
\text { como el corazón, cerebro, riñón, hígado, } \\
\text { huesos. }\end{array}$ \\
\hline Cromo & $\begin{array}{l}\text { Disminución de la actividad en- } \\
\text { zimática y crecimiento general de } \\
\text { la planta. Produce daño a nivel de } \\
\text { membrana, clorosis y daño a nivel } \\
\text { de raíz. }\end{array}$ & $\begin{array}{l}\text { - Alteraciones crónicas en el sistema ner- } \\
\text { vioso y tracto gastrointestinal del ser hu- } \\
\text { mano. } \\
\text { - Disfunciones renales producidas por la } \\
\text { necrosis de túbulos proximales o distales. } \\
\text { - Cáncer de pulmón y estómago. } \\
\text { - Daños letales y subletales por altas acu- } \\
\text { mulaciones en crustáceos. } \\
\text { Inhibición del crecimiento, supresión del } \\
\text { consumo de oxígeno, alteraciones en la } \\
\text { reproducción, muda de caparazón, así } \\
\text { como un aumento de malformaciones a } \\
\text { nivel del zooplancton. }\end{array}$ \\
\hline Mercurio & $\begin{array}{l}\text { Disminución de la actividad fotosin- } \\
\text { tética, toma de agua y enzimas an- } \\
\text { tioxidantes, acumulación de fenol y } \\
\text { prolina. }\end{array}$ & $\begin{array}{l}\text { Efectos adversos sobre el sistema inmunológi- } \\
\text { co, el sistema reproductivo, el sistema nerv- } \\
\text { ioso central causando retraso mental, sorde- } \\
\text { ra, ceguera, impedimento del habla y sobre } \\
\text { el sistema cardiovascular influyendo en la } \\
\text { presión arterial, la variedad de la frecuencia } \\
\text { cardíaca y enfermedades del corazón. }\end{array}$ \\
\hline
\end{tabular}

Tabla 2. Efectos del cadmio, el cromo y el mercurio sobre las plantas, animales y seres humanos.

Fuente: Duffus et al., 2002; Lone, 2008; Solisio, 2008; Akpor y Muchie, 2010, Kumar et al., 2012; modificado por los autores. 


\section{FORMAS EN LAS QUE ESTÁN PRESENTES LOS METALES PESADOS (Cr, Cd, Hg) EN EL AMBIENTE}

El cromo ( $\mathrm{Cr}$ ) es usado como $\mathrm{Cr}$ (III) en la industria de las curtiembres y como $\mathrm{Cr}$ (VI) en la industria maderera, este metal es altamente tóxico y carcinógeno cuando está presente a bajas concentraciones en el agua (Bolán et al., 2004) El Cr (III) es estable y se encuentra principalmente unido a materia orgánica del suelo o de ambientes acuáticos, por lo que tiene una menor movilidad. Las características de los dos estados iónicos del cromo hacen que los efectos nocivos, causados por dicho metal, sean casi en su totalidad, consecuencia de la exposición al $\mathrm{Cr}$ (IV).

En cuanto al cadmio (Cd) se conoce que su movilización anual en el mundo es de 9.039 .000 toneladas (Singh et al., 2003), la contaminación de suelos agrícolas con cadmio es de interés debido a que este metal alcanza la cadena trófica a través del uso regular de fertilizantes fosforados, siendo una fuente de este compuesto, el $\mathrm{Cd}$ en los fertilizantes fosforados se origina principalmente a partir de las rocas fosfóricas utilizadas para la elaboración de este tipo de fertilizantes. A pesar de que muchos países han definido los niveles umbral para los niveles de cadmio y otros metales en los biosólidos municipales, esos límites no han sido definidos para los fertilizantes (Bolán et al., 2014).

Las sales de cadmio son consideradas muy significativas en aguas contaminadas, no solamente por su alta toxicidad, sino por su habilidad para incorporarse en los alimentos, las plantas acuáticas y organismos mediante procesos naturales como bioacumulación y biomagnificación (Borker et al., 2013). Así mismo el Departamento de Servicios de Salud Humana de Estados Unidos propone que el cadmio sea considerado un compuesto carcinogénico (Waalkes, 2003).

El mercurio $(\mathrm{Hg})$, se encuentra en la naturaleza en sus formas inorgánicas como mercurio elemental $\mathrm{Hg}(0)$ o formas iónicas como ( $\mathrm{Hg}$ I y Hg II) y en sus formas orgánicas como dimetilmercurio $\left(\mathrm{CH}_{3}\right)_{2} \mathrm{Hg}$, fenilmercurio $\left(\mathrm{C}_{6} \mathrm{H}_{5} \mathrm{Hg}\right)$ y metilmercurio $\left(\mathrm{CH}_{3}\right) \mathrm{Hg}$. El $\mathrm{Hg}$ II tiende a unirse fuertemente con los componentes del suelo, lo cual reduce su disponibilidad; pero el metilmercurio, una de las formas orgánicas de este metal es altamente tóxico debido a su gran poder de biomagnificación, además tiene la capacidad de acumularse en membranas biológicas y debido a su liposolubilidad puede atravesar fácilmente membranas tales como las placentarias y las hematoencefálicas (Paisio et al., 2012).

Una vez que el $\mathrm{Hg}$ se ha depositado en el ambiente se incrementa el riesgo de exposición e intoxicación de los seres vivos, según Duffus, 2002 la población en general está expuesta al metilmercurio a través de su dieta, en particular, a través del consumo de pescado y productos pesqueros, en ese sentido se han registrado varios eventos de envenenamiento de personas e inclusive la muerte de las mismas (Paisio et al., 2012) 


\section{ESTRATEGIAS CONVENCIONALES PARA LA REMOCIÓN DE METALES PESADOS}

En la actualidad, debido al interés por tratar de remediar este tipo de contaminantes, se están empleando procesos fisicoquímicos para la remediación de ambientes contaminados; sin embargo, estos son costosos y no son permanentes. Las técnicas convencionales más usadas en la remediación de metales incluyen la incineración, excavación y disposición en un vertedero, sin embargo, este proceso no tiene aceptación debido a que se puede incrementar la exposición de las poblaciones cercanas al contaminante; es complicado y muy costoso encontrar nuevos sumideros para la disposición final de los desechos, además con este proceso simplemente los residuos se mueven a otro lugar con la posibilidad de crear riesgos durante la excavación, manipulación y transporte del material contaminado. La otra opción es contener las áreas contaminadas en un sitio aislado y monitoreado constantemente, aunque esto es una solución a corto plazo, debido a que la contaminación permanece en la zona (Garbisu et al., 2003).

Otras técnicas que están en desarrollo para el tratamiento de este tipo de residuos incluyen la extracción de contaminantes con solventes orgánicos o $\mathrm{CO}_{2}$, oxidación de compuestos orgánicos, vitrificación, electroreclamación, deshalogenación de compuestos orgánicos utilizando un álcali; el polietilenglicol, reducción u oxidación química del contaminante, arrastre de vapor, calefacción con microondas; solidificación/estabilización (Rulkens et al., 1998).

En América actualmente se usan y comercializan métodos físicos como la lixiviación y absorción de metales por fijación y los métodos químicos como la biorreducción y la extracción de metales con quelantes. Con la adición de quelantes sintéticos como el EDTA (ácido etilendiamina-tetraacético) tanto la solubilidad como la biodisponibilidad de los metales pesados mejora (Wu et al., 2010). La molécula quelante puede formar varios enlaces coordinados con ciertos átomos del metal aumentando su concentración y movilidad en la fase líquida del suelo, algunos iones metálicos pueden unirse fuertemente a la fase suelo y hacerse menos disponibles y de ahí la importancia del uso de quelantes. Estas aproximaciones requieren agentes químicos costosos y maquinaria con técnicos entrenados; además se ha comprobado que el uso excesivo de quelantes contamina aguas subterráneas y afecta la calidad del suelo ya que muchos iones son quelados de forma no selectiva (Wu et al., 2010).

Para el tratamiento de suelos contaminados con metales pesados existen varios métodos disponibles como la fijación que es un proceso químico que se realiza al suelo para inmovilizar los metales seguido de un tratamiento de la superficie del mismo para eliminar la penetración del agua y la lixiviación usando soluciones ácidas o agentes lixiviantes para desorber y eliminar metales del suelo para luego retornar al suelo limpio a su lugar de origen (Rajendran et al., 2003). 
De otro lado, las aproximaciones para reducir la contaminación de aguas con metales incluyen la precipitación-floculación seguido de la sedimentación y disposición del lodo resultante, el intercambio iónico, la ósmosis reversa, la microfiltración, la electrodiálisis y la evaporación (Rajendran et al., 2003). Los ambientes urbanos son los más contaminados con metales y estos son remediados actualmente mediante procesos de movilización que incluyen la fitoextracción y el lavado químico. La remoción de metales con la fitoextracción y la subsecuente recuperación del metal y su disposición segura tiene interés comercial (Lone et al., 2008; Bolán et al,. 2014; Paz-Ferreiro et al., 2014).

\section{BIORREMEDIACIÓN}

La biorremediación es un concepto general que incluye todos los procesos y acciones que se realizan con el fin de transformar un ambiente alterado por la presencia de contaminantes, el término se refiere a la utilización de organismos para degradar dichas sustancias. La biorremediación propiamente dicha utiliza principalmente microorganismos o procesos microbianos para degradar y transformar contaminantes ambientales a sustancias inofensivas o formas menos tóxicas (Garbisu et al., 2003). Estos procesos dependen de las propiedades catabólicas que presentan los microorganismos quienes utilizan los contaminantes para su desarrollo (Soto et al., 2010).

La biorremediación es una técnica basada en la existencia de microorganismos con capacidad de atacar enzimáticamente los compuestos, las estrategias pueden ser empleadas in situ y ex situ dependiendo del lugar en donde serán aplicadas, in situ es un tratamiento que se realiza en el sitio de la contaminación y ex situ se da cuando se remueve el suelo o el agua con el subsecuente tratamiento (Saadoun y Al-Ghzawi, 2005).

Las tecnologías de biorremediación de metales utilizadas actualmente pueden minimizar la biodisponibilidad y biotoxicidad de metales pesados. Dentro de estas tecnologías se destacan la bioestimulación en donde se estimula a la población microbiana nativa de la zona contaminada, la bioaumentación que es la introducción artificial de poblaciones viables a la zona, la bioacumulación utilizando células vivas y la biosorción utilizando biomasa microbiana muerta para llevar a cabo procesos de remediación de contaminantes (Rajendran et al.,2003).

Si bien esas tecnologías han sido exitosas para tratar ambientes contaminados con metales pesados, existen algunas desventajas en dichas técnicas como los efectos que se observan a largo plazo, ya que la comunidad microbiana puede ser sujeta a variación estacional debido a la exposición directa de factores ambientales cambiantes que no pueden ser controlados y la adición de nutrientes que mejora la eficiencia de algunos microorganismos, pero puede ser nocivo para la microbiota nativa (Nessner et al., 2010). Otra limitación de estos métodos es que aunque los metales son concentrados o convertidos a formas menos tóxicas ellos siguen estando presentes en el suelo y se requiere eliminarlos 
efectivamente; generalmente los productos concentrados se vierten de una forma controlada o son reciclados para la recuperación de metales (Diels et al., 1999).

Debido a que los suelos contaminados con metales pesados son difíciles de descontaminar (Cunningham et al., 1995), es bueno usar varias alternativas simultáneamente como fitorremediación en combinación con algunos microorganismos asociados a las plantas (rizorremediación) lo cual se conoce como mecanismo simbiótico. Los microorganismos que han sido objeto de estudio en el campo de la biorremediación de metales, han demostrado una alta capacidad para adaptarse y sobrevivir en ambientes contaminados con esas sustancias tóxicas. Esta resistencia generalmente se asocia con mecanismos de tipo bioquímico, aunque la existencia de genes cromosomales o plasmídicos que codifican diversas proteínas con funciones especializadas para la absorción o transformación del metal son relevantes en el proceso.

\section{RESISTENCIA Y TOLERANCIA DE LOS MICROORGANISMOS A LOS METALES PESADOS}

La toxicidad del metal depende de su biodisponibilidad, definida como su habilidad para ser transferido de un compartimento ambiental a los organismos vivos, este proceso depende de la concentración total del metal y de factores fisicoquímicos tales como el pH, la materia orgánica o contenido de arcillas y factores biológicos como la biosorción, bioacumulación y solubilización (Khade y Adholeya, 2007).

Los metales no pueden ser degradados cuando cambian su estado de oxidación como ocurre con los compuestos orgánicos tóxicos; existen solo tres mecanismos a través de los cuales un sistema biológico puede conferir resistencia a metales pesados, el primero es la disminución de la acumulación de un determinado ión mediante su transporte activo fuera de célula; el segundo es la segregación de los cationes por moléculas que contienen grupos tioles y por último se puede dar la reducción de algunos iones metálicos pesados a un estado de oxidación menos tóxico (Marrero-Coto et al., 2010).

Dentro de la amplia diversidad microbiana existen microorganismos resistentes y microorganismos tolerantes a metales, los resistentes se caracterizan por poseer mecanismos de detoxificación codificados genéticamente, constitutivos o inducidos por la presencia del metal, mientras que los tolerantes son indiferentes a la presencia o ausencia del elemento (Zeguers et al., 2001). Algunos investigadores indagaron acerca de la resistencia de bacterias a los metales pesados y encontraron que se puede deber a mecanismos de tolerancia, detoxificación y a la producción de agentes quelantes que se unen a los metales y reducen su toxicidad (Birch y Bachofen, 1990). Estas capacidades son cruciales a la hora de implementar procesos de microrremediacion en zonas contaminadas. 
Las principales estrategias de los microorganismos para protegerse contra los metales pesados incluyen la restricción de la entrada del metal dentro de la célula ya sea porque se reduce la toma del mismo, o por un eflujo activo o extrusión gracias a transportadores ubicados en membrana, que expulsan las formas nocivas desde el citoplasma celular al exterior, efectivamente se conoce que la mayoría de los sistemas de resistencia a metales se basan en el eflujo activo de iones tóxicos tales como los que expulsan iones derivados del cadmio, cobalto, cobre, entre otros (Marrero-Coto et al., 2010).

En este sistema de eflujo activo intervienen fundamentalmente tres tipos de proteínas: las facilitadoras de difusión de cationes (CDF, por sus siglas en inglés; Cation diffusion facilitator), las ATPasas tipo $\mathrm{P}$ y los transportadores de compuestos RND (por sus siglas en inglés: resistance, nodulation, cell división) que impulsan bombas de eflujo CBA que son sistemas proteicos presentes en bacterias que pueden extruir directamente iones metálicos o xenobióticos ya sea desde el citoplasma, la membrana interna del periplasma o a través de la membrana externa a el espacio extracelular (Pontel et al., 2007). Estos aparecen en gran variedad de bacterias resistentes a los metales pesados donde conforman una red muy eficiente que asegura la homeostasis celular y garantiza la supervivencia en ecosistemas con elevadas concentraciones de metales (Nies, 2003).

Otra estrategia es la acumulación y compartimentalización de iones metálicos dentro de la célula bacteriana esta puede ocurrir a nivel de la membrana, en el espacio periplasmático y en el interior celular, durante el proceso intervienen polímeros estructurales y extracelulares que interactúan con los metales atrapándolos en su interior (bioadsorción) y proteínas que se unen a los iones metálicos por los que poseen una gran afinidad evitando sus interacciones con otras proteínas esenciales para el microorganismo, gracias a este mecanismo se puede neutralizar la toxicidad del metal (Kasan, 1993).

Muchas células contienen dos tipos de sistemas de captura de cationes de metales pesados; uno es rápido e inespecífico, expresado constitutivamente y es dependiente del gradiente quimiosmótico existente a través de la membrana citoplasmática bacteriana, cuando una célula se enfrenta a altas concentraciones de un metal pesado que es acumulado por este tipo de sistema, el catión del metal pesado es transportado al citoplasma a pesar de su elevada concentración porque estos transportadores inespecíficos son constitutivos y por consiguiente esta entrada no puede cerrarse, esta puerta abierta es la primera razón del por qué los iones metálicos pesados son tóxicos; cuando el gen que codifica este sistema transportador rápido e inespecífico se muta, entonces se obtienen células que son tolerantes a metales (Marrero-Coto et al., 2010).

El segundo tipo de sistema de captura posee una gran especificidad de sustrato, es más lento y generalmente utiliza la hidrólisis de ATP como fuente de energía en adición al gradiente quimiosmótico; este sistema consumidor de energía solo se induce en la célula cuando esta lo necesita, en condiciones nutricionales desfavorables o en alguna situación metabólica especial (Marrero-Coto et al., 2010). 
Una vez dentro de la célula y cuando los metales se encuentran en exceso, pueden formar enlaces coordinados con aniones que bloquean grupos funcionales de enzimas, inhibir sistemas de transporte, desplazar metales esenciales desde los sitios nativos de enlaces e interrumpir la integridad de la membrana celular, también tienden a unirse con grupos sulfhidrilo lo cual origina la inhibición de la actividad de enzimas sensibles (Nies, 2003).

Otro efecto que se ha observado cuando la concentración intracelular de metales se incrementa en bacterias gram negativas es que esos iones pueden enlazarse al glutatión (GSH) y dar lugar a la formación de complejos que pueden reaccionar con el oxígeno molecular para generar bis-glutationato (GS-SG), el catión del metal y peróxido de hidrógeno. Debido a que la reducción del GS-SG requiere la participación del NADPH y los cationes metálicos se enlazan inmediatamente a otras moléculas de glutatión (GSH), los cationes de los metales provocan un considerable estrés oxidativo, que es en muchos casos la base de su genotoxicidad (Marrero-Coto et al., 2010).

Otras estrategias de resistencia de los microorganismos descritas por Rajendran et al., 2003 y Cervantes et al., 2006, son la formación de complejos fuera de la célula; enzimas que modifican el estado redox de los metales o los metaloides y la síntesis de proteínas de unión como metalotioneinas (MT's) y fitoquelatinas ( $\mathrm{PC}^{\prime} \mathrm{s}$ por sus siglas en ingles phytochelatins). También se ha reportado la presencia de proteínas cromadas y factores de resistencia NreB y CnrT que resultan en la transformación de metales a sus formas solubles e insolubles (Nies, 2003).

En cuanto a inmovilización extracelular de metales por parte de bacterias, se conoce que las superficies bacterianas pueden unirse a iones metálicos, esa reactividad se debe a la presencia de grupos ionizables como carboxilato o fosfato presentes en la capa de lipopolisacárido de bacterias gram negativas y el peptidoglicano y ácidos teicoicos de bacterias gram positivas, por fuera de la pared existen estructuras que también pueden interactuar con iones metálicos que están compuestas de carbohidratos como las cápsulas o capas S que están hechas de proteínas y glicoproteínas (Beveridge and Koval, 1981).

Las capas $\mathrm{S}$ recubren la superficie células de bacterias y archaeas, están compuestas de subunidades idénticas que forman una matriz porosa que puede inmovilizar ciertos iones metálicos, por medio de este proceso se pueden transformar metales a sus formas insolubles y químicamente inertes sobre todo cuando los metales se encuentran en solución (Merroun et al., 2005).

Las interacciones metal-microorganismo han sido estudiadas en el contexto de la biotecnología ambiental con el objetivo de implementar métodos de remoción, recuperación o detoxificación de metales pesados. Los microorganismos pueden realizar dos posibles transformaciones; las que dependen del estado de oxidación del metal (biolixiviación) y las que dependen de la capacidad de la inmovilización de este; las propiedades de los microorganismos resistentes, tolerantes o ambos pueden ser 
empleadas en mecanismos de inmovilización de metales pesados como los procesos de biosorción, bioacumulación, biomineralización, biotransformación y quimiosorción (Marrero-Coto et al., 2010).

\section{MICROORGANISMOS RESISTENTES Y TOLERANTES A METALES PESADOS}

Los suelos contaminados con metales pesados contienen una baja proporción de poblaciones microbianas debido a la toxicidad de esos elementos, las especies de microorganismos que pueden crecer bajo dichas condiciones tóxicas se asumen como tolerantes o resistentes a dichos metales; los términos de resistencia y tolerancia han sido usados como equivalentes pero en realidad son términos diferentes; la resistencia hace referencia a la habilidad del microorganismo para sobrevivir a los efectos tóxicos del metal por medio de mecanismos de detoxificación, mientras que tolerancia se refiere a la habilidad del microorganismo de sobrevivir frente al efecto nocivo gracias a sus propiedades intrínsecas o la modificación ambiental de la toxicidad del elemento (Dhal et al., 2013). En la tabla 3 se evidencian algunos microorganismos que pueden resistir y transformar ciertos metales pesados.

Aunque las comunidades bacterianas autóctonas son capaces de metabolizar contaminantes orgánicos y oxidar metales pesados, su baja abundancia y actividad frecuentemente se suma a la falta de acceso a contaminantes y a la limitación de nutrientes disponibles en el ambiente (Edwards et al., 2013). La existencia de esos microorganismos puede ser influenciada por varios factores como la presencia de nutrientes, pH y especialmente humedad y temperatura (Zilli et al., 2003), se conoce también que en el suelo las tasas de aireación, presencia de cultivos, estación y profundidad pueden afectar a estos microorganismos (Kavamura et al., 2010). 


\begin{tabular}{|c|c|c|}
\hline MICROORGANISMO & METAL PESADO & REFERENCIA \\
\hline $\begin{array}{l}\text { Cunninghamella echinulata, Fusarium oxyspo- } \\
\text { rum, Rhizopus stolonifer, Thrichoderma viride }\end{array}$ & $\mathrm{Cd}$ & Babich y Stotzky, 1977 \\
\hline Staphylococcus xylosus, S. carnosus & $\mathrm{Cd}$ & Samuelson et al., 2000 \\
\hline Trichoderma reesei & $\mathrm{Cd}$ & Kim et al., 2003 \\
\hline Pseudomonas aeruginosa & $\mathrm{Cd}$ & Juwarkar et al., 2007 \\
\hline $\begin{array}{l}\text { Deinococcus radiodurans, Thermus thermoph- } \\
\text { ilus, Acidiphlium angustum, Flavobacterium } \\
\text { aquatile y Flavobacterium hibernum }\end{array}$ & $\mathrm{Cd}$ & Ginn y Fein , 2008 \\
\hline Fusarium oxysporum & $\mathrm{Cd}$ & Akpor y Muchie, 2010 \\
\hline $\begin{array}{l}\text { Vibrio harveyi, Enterobacter cloacae, Rhodobi- } \\
\text { um marinum, Rhodobacter sphaeroides }\end{array}$ & $\mathrm{Cd}$ & Dash et al., 2013 \\
\hline Saccharomycetes pombe & $\mathrm{Cd}$ & Chang Lin y Lin ,2005 \\
\hline Glomus sp., Gigaspora sp., Acaulospora sp. & $\mathrm{Cd}$ & Sambandan et al, 1992 \\
\hline Pseudomonas aeruginosa & $\mathrm{Cd}$ & Rajendran et al., 2003 \\
\hline Fusarium oxysporum & $\mathrm{Cd}$ & Sanyal et al., 2005. \\
\hline Rhodobium marinum, Rhodobacter sphaeroides & $\mathrm{Cd}$ & Panwichian et al., 2011 \\
\hline Pseudomonas aeruginosa & $\mathrm{Cd}$ & Zolgharnein et al., 2010 \\
\hline Acinetobacter anitratus & $\mathrm{Cd}$ & Ahuja et al., 2001 \\
\hline Mucor sp. & $\mathrm{Cd}$ & Deng et al., 2011 \\
\hline Spirulina platensis & $\mathrm{Cd}$ & Fang et al., 2011 \\
\hline $\begin{array}{l}\text { Bacillus lichenifomis, Salmonella typhi, Pseudo- } \\
\text { monas fluorescens, Escherichia coli. }\end{array}$ & $\mathrm{Cd}$ & Ammer et al., 2014 \\
\hline Enterobacter cloacae & $\mathrm{Cr}(\mathrm{VI})$ & $\begin{array}{l}\text { Wang et al., 1989; Campos et } \\
\text { al., 1995; Frankerberg y Arshad, } \\
\text { 2001, Kavamura et al., } 2010\end{array}$ \\
\hline $\begin{array}{l}\text { Pseudomonas sp., Micrococcus sp., Bacillus sp., } \\
\text { Achromobacter sp., Microbacterium sp. , Ar- } \\
\text { throbacter sp. , Corynebacterium sp., Vogesella } \\
\text { indigofera }\end{array}$ & $\mathrm{Cr}(\mathrm{VI})$ & Dhal et al., 2013 \\
\hline Pseudochrobactrum saccharolyticum & $\operatorname{Cr}(\mathrm{VI})$ & Long et al., 2013 \\
\hline Micrococcus sp., Aspergillus sp. & $\mathrm{Cr}(\mathrm{VI})$ & Congeevaram et al., 2007 \\
\hline Pseudomonas ambígua, E.coli, C. metallidurans & $\mathrm{Cr}$ & Borremans et al., 2001 \\
\hline
\end{tabular}




\begin{tabular}{|c|c|c|}
\hline MICROORGANISMO & METAL PESADO & REFERENCIA \\
\hline $\begin{array}{l}\text { Staphylococcus aureus, Bacillus subtilis, Listeria } \\
\text { sp, E.coli, A. eutrophus, P. putida. }\end{array}$ & $\mathrm{Cr}, \mathrm{Cd}$ & Roane y Pepper, 2000 \\
\hline Aspergillus sp. Rhizopus sp. & $\mathrm{Cd}$ y $\mathrm{Cr}$ & Ahmad et al., 2005 \\
\hline $\begin{array}{l}\text { Aeromonas sp., Staphylococcus aureus, Lacto- } \\
\text { bacillus sp., Micrococcus sp., Bacillus sp., Bacil- } \\
\text { lus megaterium, Acinetobacter sp., Pseudomo- } \\
\text { nas aeruginosa, Escherichia coli }\end{array}$ & $\mathrm{Cd} \mathrm{y} \mathrm{Cr}$ & Ali et al., 2009 \\
\hline Geobacillus thermodenitrificans & $\mathrm{Cd}$ y $\mathrm{Cr}$ & Chatterjee et al., 2010 \\
\hline Shewanella oneidensis & $\mathrm{Hg}(\mathrm{II})$ & Wiatrowski et al., 2006 \\
\hline Chlamydomonas reinhardtii & $\mathrm{Hg}(\mathrm{II})$ & Bayramoglu y Arica, 2008 \\
\hline Trichoderma harzianum & $\mathrm{Hg}(\mathrm{II})$ & Raspanti et al., 2009 \\
\hline Pseudomonas sp., Psychrobacter sp. & $\begin{array}{l}\text { Hg orgánico e } \\
\text { inorgánico }\end{array}$ & Pepi et al., 2011 \\
\hline P. balearica & $\begin{array}{l}\text { Me Hg (metil } \\
\text { mercurio) }\end{array}$ & Lee et al., 2011 \\
\hline P. putida V1 & $\begin{array}{l}\text { Me Hg (metil } \\
\text { mercurio) }\end{array}$ & Cabral et al., 2012 \\
\hline $\begin{array}{l}\text { P. fluorescens, Enterobacter cloacae, Citrobacter } \\
\text { braakii, Alcaligenes faecalis }\end{array}$ & $\begin{array}{l}\text { Me Hg (metil } \\
\text { mercurio) }\end{array}$ & Adelaja y Keenan, 2012 \\
\hline Enterobacter sp., Bacillus cereus & $\mathrm{Hg}(\mathrm{II})$ & Sinha y Khare, 2012 \\
\hline Bacillus sp. & $\begin{array}{l}\mathrm{Cd}, \mathrm{Cr} \mathrm{y} \\
\mathrm{Hg}\end{array}$ & Cañizares, 2000 \\
\hline
\end{tabular}

Tabla 3. Microorganismos que pueden resistir y transformar $\mathrm{Cd}$, $\mathrm{Cr}$ y $\mathrm{Hg}$

Fuente: Los autores.

\section{PLANTAS METALOFITAS O HIPERACUMULADORAS}

Algunas especies vegetales tienen la capacidad de crecer en suelos y aguas contaminadas con metales pesados, además presentan la habilidad de acumular una elevada cantidad de estas sustancias mediante adaptaciones fisiológicas, estas plantas reciben el nombre de metalofitas o hiperacumuladoras de metales (Maiti et al., 2004). Las plantas metalófitas pueden acumular metales de 100 a 500 veces más que otras especies vegetales y se caracterizan por presentar diferentes mecanismos biológicos para tolerar elevadas concentraciones de metales, alcanzando niveles de remoción de hasta el 100\% (Chaney et al,. 2007, Maiti et al., 2004; Kavamura y Esposito, 2010), estudios indican que este tipo de 
plantas pueden almacenar en promedio $100 \mu \mathrm{g} / \mathrm{g}(0.01 \%$ peso seco) de Cd y As; $1000 \mu \mathrm{g} / \mathrm{g}(0.1 \%$ peso seco) de $\mathrm{Co}, \mathrm{Cu}, \mathrm{Cr}$, Ni y Pb; y $10000 \mu \mathrm{g} / \mathrm{g}$ de Mn (1.0 \% peso seco) (McGrath et al., 2001; Padmavathiamma y Li, 2007). Según Paz-Ferreiro et al., (2014), estas plantas pueden almacenar más de $100 \mathrm{mg} /$ $\mathrm{kg}$ en peso seco de $\mathrm{Cd}$, más de $1000 \mathrm{mg} / \mathrm{kg}$ de $\mathrm{Cu}, \mathrm{Co}, \mathrm{Cr}$, Ni o $\mathrm{Pb}$ y más de $10000 \mathrm{mg} / \mathrm{kg}$ de Mn o Zn.

Las mejores especies adaptadas a estas condiciones se identifican según fenología, metabolismo y microorganismos asociados (McGrath et al., 2001; Padmavathiamma y Li, 2007, Ücüncii et al., 2013). Más de 400 especies vegetales han sido identificadas como hiperacumuladoras, incluidas 300 especies que acumulan $\mathrm{Ni}$ y se conoce que algunas plantas tienen la capacidad de acumular $\mathrm{Cd}, \mathrm{Cu}, \mathrm{Pb}$ y Zn (Li et al., 2003, Ücüncii et al., 2013).

La mayoría de las especies fitorremediadoras se encuentran taxonómicamente dentro de los órdenes Brassicales, Asterales, Solanales, Poales, Malpighiales, Fabales, Caryophyllales y Rosales (Paz-Ferreiro et al., 2014). La familia Brassicaceae es de especial interés ya incluye plantas hiperacumuladoras que no son palatables para los animales, lo que puede reducir los procesos de bioacumulación de metales en la cadena alimenticia durante los programas de fitoextracción (Navari-izzo y Quartaccim, 2001).

Como regla general, los metales rápidamente biodisponibles para las plantas son $\mathrm{Cd}, \mathrm{Ni}, \mathrm{Zn}$, As, Se y $\mathrm{Cu}$, los moderadamente disponibles son $\mathrm{Co}, \mathrm{Mn}$ y $\mathrm{Fe}$; mientras que el $\mathrm{Pb}, \mathrm{Cr}$ y $\mathrm{Hg}$ no son biodisponibles (Miller y Bassler, 2001). La habilidad de acumular metales pesados varía significativamente entre especies, cada una desarrolla diferentes mecanismos para transformar los iones, según sus características morfológicas, fisiológicas, genéticas y anatómicas (Borker et al., 2013; Swain et al., 2014).

La bioacumulación de metales y metaloides en las plantas ocurre por mecanismos de adsorción y absorción; los cuales son conocidos como "bioacumulacion". Estos procesos permiten que las plantas puedan capturar sustancias de diversos ambientes a través de intercambio iónico, complejación superficial y precipitación (Favas et al., 2012). Las plantas hiperacumuladoras absorben metales pesados en diferentes rangos mediante estrategias de translocación a través de tonoplastos y acumulación en vacuolas, los cuales protegen el metabolismo celular del efecto nocivo por metales tóxicos (Maiti et al., 2004).

Saeth en el 2012, menciona que algunas plantas necesitan nutrientes esenciales como el $\mathrm{Zn}^{+2}$; sin embargo, la planta no tiene la capacidad de hacer una toma selectiva, permitiendo el libre paso de otros metales divalentes a las partes aéreas, lo que puede contribuir a apartar algunos depredadores como nematodos y microorganismos fitopatógenos. Es posible que las plantas hiperacumuladoras presenten una codificación genética particular, que permita la acumulación del metal en sus tejidos de raíces, tallos y hojas de acuerdo con la concentración presente en el medio (Kavamura y Espósito, 2010; Akpor y Muchie, 2010). 


\section{PLANTAS RESISTENTES Y TOLERANTES A LOS METALES PESADOS}

En algunas zonas, la contaminación del suelo y agua por metales pesados o micronutrientes se encuentra en concentraciones fitotóxicas, lo que permite que algunas plantas puedan tener la capacidad de adaptarse y colonizar ambientes con altas concentraciones de metales pesados, hasta acumularlas en sus tejidos. Diferentes concentraciones de metales inducen diversas respuestas en las plantas, en los casos donde están expuestas a altas concentraciones, se genera inhibición de las enzimas involucradas en reacciones de fotosíntesis (Rascio y Navari-lzzob, 2011; Borker et al., 2013).

Maiti y colaboradores en el 2004 estudiaron los mecanismos desarrollados por las plantas para tolerar elevadas concentraciones del metal sin causar alteraciones metabólicas, dependiendo del tipo de metal al que esté expuesta la vegetación tendrá una respuesta particular mediante las enzimas que están involucradas en los procesos de fotosíntesis. Algunas respuestas de las plantas para tolerar el estrés metálico son la síntesis de peroxidasas y catalasas (Kumar, 2012), la acumulación de fitoquelatinas en las vacuolas, la liberación de compuestos orgánicos mediante la raíz y producción de ácidos orgánicos como ácido cítrico y ácido málico (Maiti et al., 2004).

Algunas investigaciones evidencian los mecanismos fisiológicos involucrados en la respuesta de las plantas a la exposición de los metales pesados. Li et al., (2000), estudiaron el posible rol de mucilago en la protección de raíces ante el aluminio (Al), estos bioensayos muestran que las células con formación callosa no fueron afectadas por el Al, aunque el crecimiento de las raíces fue inhibido. Otros estudios realizados por Rauser en 1999, trabajando con mutantes de la especie Arabidopsis thaliana, evidencian el rol de las fitoquelatinas que son péptidos ricos en ácido glutámico y cisteína sobre la tolerancia a los metales pesados.

Baghour et al., (2001) analizaron la respuesta de las plantas frente a diferentes temperaturas del suelo, demostrando diversas respuestas en las raíces ante concentraciones de metales como $\mathrm{Cd} \mathrm{y} \mathrm{Pb}$, presentándose una mejor eficiencia de fitoacumulación entre $\operatorname{los} 23^{\circ} \mathrm{C}$ y $27^{\circ} \mathrm{C}$. En la tabla 4 se presentan diferentes especies de plantas con la capacidad de resistir y transformar ciertos metales pesados. 


\begin{tabular}{|c|c|c|}
\hline PLANTA & METAL PESADO & REFERENCIA \\
\hline Salvinia natans Kunth. & $\mathrm{Cd}$ & Buta et al., 2014 \\
\hline Elodea canadensis Michx. & $\mathrm{Cd}$ & Buta et al., 2014 \\
\hline Pistia stratiotes $L$. & $\mathrm{Cd}$ & $\begin{array}{l}\text { Prasand y Freitas, 2003; Buta et al., 2014, } \\
\text { Kumar et al., 2012. }\end{array}$ \\
\hline Spirulina platensis & $\mathrm{Cd}$ & Solisio et al., 2007 \\
\hline Thlapsi sp. & $\mathrm{Cd}$ & Prasand y Freitas, 2003 \\
\hline Thlaspi caerulescens & $\mathrm{Cd}$ & Whithing et al., 2000 \\
\hline Spirulina platensis & $\mathrm{Cd}$ & Solisio et al., 2007 \\
\hline $\begin{array}{l}\text { Brassica sp, Alyssum sp., Arabidopsis sp, } \\
\text { Petrisis sp }\end{array}$ & $\mathrm{Cr}$ & Kamnev y van der Lelie, 2000. \\
\hline Ipomoe aquiatica & $\mathrm{Cr}$ & Weerasinghe et al., 2008 \\
\hline Helianthus annuus & $\mathrm{Cd}, \mathrm{Cr}$ & January et al., 2008 \\
\hline $\begin{array}{l}\text { Limnocharis flava, Thalia geniculate, Typha } \\
\text { latifolia }\end{array}$ & $\mathrm{Hg}$ & Anning et al., 2013. \\
\hline Eichhornia crassipes Mart. & $\mathrm{Cd}, \mathrm{Cr}, \mathrm{Hg}$ & $\begin{array}{l}\text { Zhu et al., 1999; Dos Santos y Lenzi, 2000; } \\
\text { Prasand y Freitas, 2003; January et al., } \\
\text { 2008, Jafari, 2010; Mane et al., 2011; Car- } \\
\text { rión et al., 2012, Kumar et al., 2012; Saleth, } \\
\text { 2012; Sood et al., 2012; Borker et al., } \\
\text { 2013; Buta et al., 2014; Swain et al., } 2014\end{array}$ \\
\hline Lemna minor $L$. & $\mathrm{Cd}, \mathrm{Cr}, \mathrm{Hg}$ & $\begin{array}{l}\text { Prasand y Freitas, 200), Kumar et al., 2012; } \\
\text { Bharti y Banerjee, 2013; Ücüncii et al., } \\
\text { 2013, Buta et al., 2014 }\end{array}$ \\
\hline Azolla pinnata & $\mathrm{Cd}, \mathrm{Cr}, \mathrm{Hg}$ & Kumar et al., 2012, Bharti y Banerjee,2013 \\
\hline
\end{tabular}

Tabla 4. Especies de plantas que pueden resistir y transformar $\mathrm{Cd}$, $\mathrm{Cr}$ y $\mathrm{Hg}$.

Fuente: Los autores.

\section{Mecanismos bioquímicos de tolerancia a los metales pesados}

Los metales pesados inducen cambios bioquímicos en plantas, en especies sensibles causan inhibición en las reacciones fotosintéticas. La gran acumulación de metales pesados genera adaptaciones ecofisiológicas, las cuales han permitido la formación de compuestos bioquímicos proteína-metal llamados metalotioneínas, estas constituyen la familia de metaloproteínas y metal-péptido con bajo peso molecular que son responsables de la regulación interna de micronutrientes como $\mathrm{Zn}$ y $\mathrm{Cu}$, 
además sirven de protección a la célula de los efectos tóxicos de metales como $\mathrm{Cd}, \mathrm{Hg}, \mathrm{Cr}$ (Maiti et al., 2004).

Dentro de las metalotioneinas se encuentran las fitoquelatinas (FQ), familia de péptidos de bajo peso molecular que involucran la acumulación, detoxificación y metabolismo de algunos metales como $\mathrm{Cd}, \mathrm{Zn}, \mathrm{Cu}, \mathrm{Pb}$ y Hg en las células de las plantas (Maiti et al., 2004). La constitución química de las

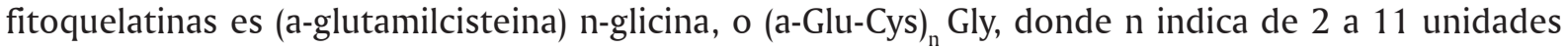
repetitivas. Se ha demostrado que la biosíntesis de FQ se genera después de la activación metálica de enzimas que utilizan glutatión como sustrato. Esta enzima es glutamilcisteina transpeptidasa, conocida como FQ sintetasa se ha estudiado principalmente in vitro adicionando agentes quelantes como EDTA (Wu et al., 2010).

La selección apropiada de especies de plantas y la manipulación de la rizósfera son factores claves para desarrollar tecnologías de fitoextracción. Bricker et al., (2001), reportaron la fitoextracción de $\mathrm{Pb}$ y Cd de superficies de suelo es más eficiente al utilizar compuestos quelantes como EDTA (2\%) y citrato. Esta técnica es reconocida y utilizada porque permite el crecimiento de microrganismo asociados a las plantas, además se puede usar en plantas con bajo potencial de fitoextracción. En los estudios realizados con EDTA se incrementa la concentración del metal en las especies de plantas después de aplicar el agente quelante, debido a que favorece la translocación del metal desde la raíz hasta las partes verdes de la planta.

\section{Biotecnología e ingeniería genética}

El uso de ingeniería genética para modificar las características de las plantas hiperacumuladoras mejora la toma y transporte del metal, de esa forma se mejoran los procesos de biodegradación de contaminantes y se favorece el crecimiento vegetal; estas aproximaciones pueden ser viables dependiendo del sustrato y las condiciones en que se realicen los procesos de biorremediación. En algunos casos el éxito de la remoción de estos metales ha sido a partir de la modificación genética mejorando la resistencia y la fitoextracción a partir de las metalotioneinas (Samantaray et al., (2001).

Lee et al., (1997), demostró la remoción de metales pesados como $\mathrm{Cu}, \mathrm{Pb}, \mathrm{Cd}$ y Ni, en aguas residuales utilizando macrófitas con un porcentaje de eliminación del 50\%, las estrategias utilizadas se relacionan con la fitoextracción, la rizosecreción; así como la producción y síntesis de productos naturales y proteínas recombinantes de las raíces a nivel de laboratorio. Samantaray et al., (2001), trabajando con Echinochloa colona desarrollaron tolerancia al $\mathrm{Ni} \mathrm{y} \mathrm{Cr}$ realizando cultivo de tejidos de brotes y regeneración de la planta in vitro, por medio de la trasferencia de caracteres para la hiperacumulación de metales, esto fue posible gracias a técnicas como la hibridación somática, en la cual se obtienen plantas híbridas a partir de la fusión de protoplastos derivados de células somáticas. Bidwell et al., (2001), desarrollaron un protocolo de micropropagación de hiperacumulación al Ni utilizando la especie Hybanthus floribundus clonando brotes y obteniendo cultivos con la habilidad de hiperacumular Ni. 
Diferentes proteínas transportadoras juegan un rol importante en la exclusión y toma de metales no esenciales como $\mathrm{Cd}$, por lo que se han diseñado proteínas a nivel de laboratorio con múltiples aplicaciones que permitan acumular ciertos cationes y excluir otros. Un número importante de proteínas transportadoras pertenece a los genes ZIP, identificados por su importante rol en la exclusión, toma y detoxificación de metales (Francova et al., 2001).

El uso de plantas transgénicas ha sido desarrollado en biorremediación de metales y compuestos orgánicos. De la Fuente y Herrera, (1993) fueron los primeros en utilizar transgénicos con la capacidad de secuestrar ácidos orgánicos que permiten tolerar altas concentraciones de $\mathrm{Al}$ (Francova et al., 2001). El conocimiento de la fisiología, bioquímica y biología molecular de la planta en respuesta a contaminantes específicos es crítico para la optimización y avances en fitoremediación.

\section{CONCLUSIONES}

La contaminación de metales pesados a causa de actividades antrópicas tales como la fabricación de solventes orgánicos, pesticidas, pigmentos, plásticos, combustibles entre otros, ha generado una problemática ambiental y sanitaria. Debido a sus propiedades altamente tóxicas que pueden ocasionar variedad de patologías en el ser humano e incluso generar diversos tipos de cáncer, se requiere con urgencia la implementación de tecnologías de tratamiento rentables y de bajo impacto ambiental como las que involucran el uso de organismos vivos. El uso de plantas hiperacumuladoras y de microorganismos tolerantes y resistentes a los metales pesados pueden ser una estrategia prometedora para mitigar el efecto nocivo de estos contaminantes. 


\section{REFERENCIAS BIBLIOGRÁFICAS}

Abollino, O., Aceto, M., Malandrino, M., Mentaste, E., Sarzanini, C. y Barberis, R. (2002). Distribution and mobility of metals in contaminated sites. Chemometric Investigation of Pollutant Profiles. Environ Pollut, 119(2):177-93.

Adelaja, O., Keenan, H. (2012). Tolerance of TBT-resistant bacteria isolates to methylmercury. Res J Environ Sci 6(1):1-13.

Adeniji, A. (2004). Bioremediation of arsenic, chromium, lead and mercury. National network of environmental management studies fellow for U.S. Environmental protection agency. Washington.

Ahmad. I., Zafar, S. y Ahmad, F. (2005). Heavy metal biosorption potential of Aspergillus and Rhizopus sp. isolated from wastewater treated soil. J. Appl. Sci. Environ. Mgt. 9 (1): 123 - 126.

Ahuja, V., Vohra, P., Kashyap, D. y Tewari, R. (2001). Adsorption of heavy metals $\left(\mathrm{Pb}^{+2}\right.$ and $\left.\mathrm{Cd}^{+2}\right)$ by free and inmovilized biomass of Acinetobacter anitratus. IJM 41(1):275- 279.

Akpor, O. y Muchie, M. (2010). Remediation of heavy metals in drinking water and wastewater treatment systems: Processes and aplications. International. J. phys. Sci. 5(12):1807-1817.

Ali, N., Hameed, A. y Ahmed, S. (2009). Physicochemical characterization and bioremediation perspective of textile effluent, dyes and metals by indigenous bacteria. J. Hazard. Mater. 164(1): 322-328.

Ameer, S. y Rajaganesh, K. (2014). Microbial bioremediation of heavy metals from textile industry dye effluents using isolated bacterial strains. Int.J.Curr.Microbiol.App.Sci 3(5): 785-794

Anning, A., Korsah, P. y Addo, P. (2003). Phytoremediation of wastewater with Limnocharis Flava, Thalia Geniculata and Typha Latifolia in constructed wetlands. INT J Phytoremediat 15 (5): 452-464.

Babich, H. y Stotzky, G. (1977). Effect of cadmium on fungi and on interactions between fungi and bacteria in soil: influence of clay minerals and pH. Appl. Environ. Microbiol. 33:1059-1066.

Baghour, M., Moreno, D., Villora, G., Hernández, J., Catilla, N. y Romero, L. (2001). Phytoextraction of $\mathrm{Cd}$ and $\mathrm{Pb}$ and physiological effects in potato plants (Solanum tuberosum var. Spunta): Importance of root temperature. J. Agric. and Food. Chem. 49 (5356-5363).

Bayramoglu, G. y Arica, M. (2008). Removal of heavy mercury (II), cadmium (II) and zinc (II) metal ions by live and heat inactivated Lentinus edodes pellets. Chem. Eng. Journal.143:133-140.

Beveridge, T. and Koval, S. (1981). Binding of metals to cell envelopes of Escherichia coli K12. Appl. Environ. Microbiol. 42:325-335. 
Bharti, S. y Banerjee, T. (2013). Bioassay analysis of efficacy of phytoremediation in decontamination of coal mine effluent. Ecotox. Environ. Safe. 92: 312-319.

Bidwel, S., Pederick, J. y Sommer-Knudsen, W. (2001). Micropropagation of the nickel hyperaccumulator Hybanthus floribundus (family Violaceae), plant cell tissue and organ. Cult 67: 89-92.

Birch, J. y Bachofen, R. (1990). Complexing agents form microorganisms. Cell. Mol. Life. Sci. 45:827-834.

Bolan, N., Kunhikrishnan, A., Thangarajan, R., Kumpiene, J., Park, J., Makino, T., Kirkham, M. y Scheckel K. (2014). Remediation of heavy metal(loid)s contaminated soils-To movilize or to inmovilize. J. Hazard. Mater. 266:141-166.

Borker, A., Mane. A., Saratale, G. y Pathade, G. (2013). Phytoremediation potential of Eichhornia crassipes for the treatment of cadmium in relation with biochemical and water parameters. Emir. J. Food. Agric. 25 (6): 443-456.

Borremans, B., Hobman, J., Provoost, A., Brown, N. y van derLelie D. (2002). Cloning and functional analysis of the pbr lead resistance determinant of Ralstonia metallidurans CH34. J. Bacteriol 183:5651-5658.

Bricker, T., Pichtel, J., Brown, H. y Simmons, M. (2001). Phytoextraction of Pb and Cd from a superficial soil: effects of amendments and croppings. J. Environ .Sci. Heal. E. 36: 1597-1610.

Bruins, M., Kapil, S. y Oehme, F. (2000). Microbial resistance to metals in the environment. Ecotoxicol. Environ. Saf.45:198-207.

Buta, E., Török, A., Csog, A., Zongo, B., Cantor, B., Buta, M. y Majdik, M. (2014). Comparative studies of the phytoextraction capacity of five aquatic plants in heavy metal contaminated water. Not. Bot. Horti. Agrobo. 42(1):173-179.

Cabral, L., Giovanella, P., Gianello, C., Bento, F., Andreazza, R y Camargo, F. (2012). Isolation and characterization of bacteria from mercury contaminated sites in Rio Grande do Sul, brazil, and assessment of methylmercury removal capability of a Pseudomonas putida V1 strain. Biodegradation 24(3):319-31.

Campos, J., Martínez, M y Cervantes, C. (1995). Hexavalent chromium reduction by a chromate-resistant bacillus strain. Anton. Leeuw. 68:203-208.

Cañizares, R. (2000). Biosorción de metales pesados mediante el uso de biomasa microbiana. Rev. Lat. Microbiol. 42:131-143.

Carrión, C., Ponce-de León, C., Cram, C., Sommer, I., Hernández, M. y Vanegas, C. (2012). Potential use of water hyacinth (Eichhornia crassipes) In xochimilco for metal phytoremediation. Agrociencia 46: 609-620. 
Cervantes, C., Espino, A., Acevedo, F., León, I., Rivera, M. y Ávila M. (2006). Interacciones microbianas con metales pesados. Rev. Lat. Microbiol 48(2): 203-210.

Chaney, R., Angle, J., Broadhurst, C., Peters, C., Tapero, R. y Sparks, D. (2007). Improved understanding of hyperacumulation yields commercial phytoextraction and phytomining technologies, J. Environmental Qual, 36: (1429-1443).

Chang, L. y Lin H. (2005). Remediation of soil contaminated with the heavy metal $\left(\mathrm{Cd}^{2+}\right)$. J. Hazard. Mater A122 7-15.

Chatterjee, S., Bhattacharjee y I., Chandra, G. (2010). Biosorption of heavy metals from industrial waste water by Geobacillus Thermodenitrificans. J. Hazard. Mater. 175: 117-125.

Congeevaram, S., Dhanarani, S., Park, J., Dexilin, M. y Thamaraiselvi K. (2007). Biosorption of chromium and nickel by heavy metal resistant fungal and bacterial isolates. J. Hazard. Mater. 146: 270-277.

Cunningham, S., Berti, W., Huang J. (1995). Phytoremediation of contaminated soils. Trends Biotechnol 13:393-397.

Dash, H., Mangwani, N., Chakraborty, J., Kumari, S. y Das, S. (2013). Marine bacteria: potential candidates for enhanced bioremediation. Appl. Microbiol. Biotechnol. 97:561-571.

Deng, Z., Cao, L., Huang, H., Jiang, X., Wang, W., Shi, Y y Zhang R. (2011). Characterization of Cd- and $\mathrm{Pb}$-resistant fungal endophyte Mucor sp. CBRF59 isolated from rapes (Brassica chinensis) in a metal-contaminated soil. J. Hazard. Mater. 185: 717-724.

De la Fuente-Martínez, M. y Herrera-Estrella, L. (1993). Strategies to design transgenic plants resistant to toxins produced by pathogens. Ag. Biotech. News. Inf. 5:295-299.

Dhal, B., Thatoi, H., Das, N. y Pandey, B. (2013). Chemical and microbial remediation of hexavalent chromium form contaminated soil and mining/metallurgical solid waste: A review. J. Hazard. Mater. 250-251:272-291.

Diels, L., De Smet, M., Hooyberghs, L. y Corbisier, P. (1999). Heavy metals bioremediation of soil. Mol. Biotechnol. 12:149-158.

Dos Santos, M. y Lenzi, E. (2000). The use of aquatic macrophytes (Eichhornia crassipes) as a biological filter in the treatment of lead contaminated effluents. Environ. Technol. 21:15-622.

Duffus, J. (2002). Heavy Metals”A Meaningless Term? (IUPAC Technical Report). Pure. Appl. Chem. 74 (5):793-807. 
Edwards, S y Kjellerup, B. (2013). Applications of Biofilms in bioremediation and biotransformation of persistent organic pollutants, pharmaceuticals/personal care products and heavy metals. Appl. Microbiol. Biotechnol. 97:9909-9921.

Fang, L., Zhoub, Ch., Caib, P., Chena, W., Rongb, X., Daib, K., Liangb, W., Guc, J. y Huanga Q. (2011). Binding characteristics of copper and cadmium by cyanobacterium Spirulina Platensis. J. Hazard. Mater 190 (2011) 810-815

Favas, P., Pratas, J. y Prasad, M. (2012). Accumulation of arsenic by aquatic plants in large-scale field conditions: Opportunities for phytoremediation and bioindication. Sci. Total. Environ. 433: 390397.

Francova, M., Demnerova, K., Muralidharan, N y Riley, K. (2001). Transgenic plant technology showed many obvious advantages over conventional plant breeding approaches to crop improvement. Chem. list 95:630-637.

Frankenberger, W y Arshad, M. (2001). Bioremediation of selenium contaminated sediments and water. Biofactors 14: 241-254.

Garbisu, C y Alkorta, I. (1997). Bioremediation: principles and future. J. Clean Technol. Environ. Toxicol. Occup. Med. 6:1-16.

Garbisu, C y Alkorta, I. (2003). Basic concept son heavy metal soil bioremediation. Eur. J. Min. Process. Environ. protection. 3 (1): 58-66.

Ginn, B. y Fein, J. (2008). The effect of species diversity on metal adsorption onto bacteria. Geochim. Cosmochim. Acta 72: 3939-3948.

Jafari, N. (2010). Ecological and socio-economic utilization of water hyacinth (Eichhornia crassipes Mart Solms). J Appl Sci Env Manage 14 (2): 43-49.

January, M., Cutright, T., Van Keulen, H. y Wei, R. (2008). Hydroponic phytoremediation of Cd, Cr, Ni As and and Fe: can Helianthus annuus hyperaccumulate multiple heavy metals? Chemosphere. 70 (3):531-7.

Juwarkar, A., Nair, A., Dubey, K., Singh, S. y Devotta, S. (2007). Biosurfactant technology for remediation of cadmium and lead contaminated soils. Chemosphere 68:1996-2002.

Kamnev, A y Van der Lelie, D. (2000). Chemical and biological parameters as tools to evaluate and improve heavy metal phytoremediation. Biosci. Rep. 29: 239-258.

Kasan, H. (1993). The role of waste activated sludge and bacteria in metal-ion removal from solution. Crit. Rev. Environ Sci Technol 23:79-117. 
Kavaruma, V. y Espósito E. (2010). Biotechnological strategies applied to the decontamination of soils polluted with heavy metals. Biotech. Advan 28:61-69.

Khade, S. y Adholeya, A. (2007). Feasible bioremediation through arbusculares mycorrhizal fungi imparting heavy metal tolerance: a retrospective. Sssa. Spec. Publ. 11(1)33-43.

Kim, S., Park, C., Koo, Y. y Yun, H. (2003). Biosorption of cadmium and cooper ions by Trichoderma reesei RUT C30.J Ind Eng Chem 9:403-406.

Kumar, S., Neelima, M y Sing, S. (2012). Phytorremediation of chromium and cobalt using Pistia sratiotes: A sustainable approach. Proc. Int. Acad. Ecol. and Environ. Sci. 2 (2): 136-138.

Lamb, D., Ming, H., Megharaj, M. y Naidú, R. (2009). Heavy metal (Cu, Zn, Cd and Pb) partitioning and bioaccessibility in uncontaminated and long-term contaminated soils. J. Hazard. Mater. 171: 11501158.

Lee, Chon-Lin. (1997). Heavy metals removal by a promising locally available aquatic plant. Wat. Sci, Tech. 39: 177-181.

Lee, S., Chung, J., Won, H., Lee, D. \& Lee, Y. (2012). Removal of the methylmercury and tributyltin (TBT) using marine microorganisms. Bull Environ Contam Toxicol 88:239-244.

Li, X., Feng, M. y Syuntaro, H. (2000). Mucilage strongly binds aluminum but does not prevent roots from aluminum injury in Zea mays. Physiology Planetarium 108 (152-160).

Li, Y., Chaney, R., Brewer, E., Roseberg, R., Angle, J., Baker, A., Reeves, R. y Nelkin J. (2003). Development of a technology for commercial phytoextraction of nickel: economic and technical considerations. Plant. Soil. (249):107-115.

Lone, M., Zhen-li, He., Stoffella, P. y Yang X. (2008). Phytoremediation of heavy metal polluted soils and water: Progresses and perspectives. J Zhejiang Univ Sci B. 9(3): 210-220.

Long, D., Tanga, X., Caib, K., Chena, G., Chena, L., Duana, D., Zhuc, J. y Chena, Y. (2013). Cr(VI) reduction by a potent novel alkaliphilic halotolerant strain Pseudochrobactrum saccharolyticum LY10 J. Hazard. Mater. 256- 257: 24- 32.

Lucho, C., Álvarez, M., Beltrán, R., Prieto, F. y Poggi, H. (2005). A multivariate analysis of the accumulation and fractionation of major and trace elements in agricultural soils in Hidalgo State, Mexico irrigated with raw wastewater. Environ. Int. 31(3): 313-323.

Maiti, R., Hernández, J., González, J. y López, D. (2004). Plant based biorremediation and mechanims of heavy metals tolerance of plants: a review. Proc Indian natn Sci Acad. B70 1: 1-12. 
Mancera, N. y Álvarez, J. (2006). Estado del conocimiento de las concentraciones de mercurio y otros metales pesados en peces dulceacuícolas de Colombia. Acta Bio Col. 11 (1): 3 - 23.

Mane, A., Saratale, V., Karadge, B. y Samant, S. (2011). Studies on the effects of salinity on growth, polyphenol content and photosynthetic response in Vetiveria zizanioides (L.) Nash. Emir. J. Food Agric. 23:59-70.

Marrero, J., Díaz, A. y Coto O. (2010). Mecanismos moleculares de resistencia a metales pesados en las bacterias y sus aplicaciones en la Biorremediación. Revista CENIC 41(1):67-78.

McGrath, SP., Zhao, FJ y Lombi E. (2001). Plant and rhizosphere process involved in phytoremediation of metal-contaminated soils. Plant Soil. 232 (1/2): 207-214.

Merroun M., Raff J., Rossberg A., Hennig C., Reich T. and Selenska-Pobell S. (2005). Complexation of Uranium by Cells and S-Layer Sheets of Bacillus sphaericus JG-A12 Appl. Environ. Microb. 71(9):55325543.

Miller, M. y Bassler B. (2001).Quorum sensing in bacteria. Annu Rev Microbiol 55:165-199.

Navari-Izzo, F. y Quartacci, M. (2011). Phytoremediation of metals. Minerva Biotechnol.13: 73-83.

Nessner, V. y Espósito E. (2010). Biotechnological strategies applied to the decontamination of soil polluted with heavy metals. Biotech. Adv. 28:61-89.

Nies, D. (2003). Efflux-mediated heavy metal resistance in prokaryotes. FEMS Microbiol Rev. 27:313339.

Noreña, D. (2012). Heavy metals (Cd, Pb and $\mathrm{Ni}$ ) in fish species commercially important from Magdalena river, Tolima tract, Colombia. Tumbaga, 2 (7):1909-4841.

Padmavathiamma, Py Li, L. (2007). Phytoremediation Technology: Hyperaccumulation metals in plants. Water, Air, Soil, Pol. 184: 105-126.

Paisio, C., González, P., Talano, M. y Agostini E. (2012). Remediación biológica de mercurio: recientes avances. Rev Latinoam. Biotecnol. Amb. Algal 3(2): 119-146.

Panwichian, S., Kantachote, D., Wittayaweerasa, B. y Mallavarapu, M. (2011). Removal of heavy metals by exopolymeric substances produced by resistant purple non sulphur bacteria isolated from contaminated shrimp ponds. Electron J. Biotechnol 14: ISSN: 0717-3458.

Parra, J. y Espinosa, L. (2010). Distribución de metales pesados ( $\mathrm{Pb}, \mathrm{Cd}$ y $\mathrm{Zn}$ ) en perfiles de sedimento asociado a Rhizophora mangle en el Río Sevilla - Ciénaga Grande de Santa Marta, Colombia. Bol. Invest. Mar. Cost. 37(1): 95-110. 
Espinosa, L.; Parra, J. y Villamil, C. (2011). Determinación del contenido de metales pesados en las fracciones geoquímicas del sedimento superficial asociado a los manglares de la ciénaga grande de Santa Marta, Colombia. Bol. Invest. Mar. Cost. 40 (1): 7-23.

Paz-Ferreiro, J., Lu, H., Fu, S., Méndez, A. y Gascó, G. (2014). Use of phytorremediation and biochar to remediate heavy metal polluted soils: a review. Solid. Earth. 5: 65-75.

Pepi, M., Gaggi, C., Bernardirni, E., Focardi, G., Lobianco, A., Ruta, M., Nicolardi, V., Volterrani M. y Gasperini, S. (2011). Phytoextraction of cadmium and zinc from a metal-contaminated soil by mycorrhizal willows. Int J Phytoremediat 11:200-213.

Pontel L., Pérez M., Espariz A., Checa S. and Soncini F. (2007). GolS controls the response to gold by the hierarchical induction of Salmonella-specific genes that include a CBA efflux-coding operon. Mol. Microbio. 66(3) 814-825

Prasad, M. \& Freitas, H. (2003). Metal hyperaccumulation in plants- Biodiversity prospecting for phytoremediation technology. Electron. J. Biotechnol 93(1):285-321.

Ragnarsdottir, K. y Hawkins, D. (2005). Trace metals in soils and their relationship with scrapie occurrence. Geochim. Cosmochim. Acta 69:A194-A196.

Rajapaksha, R., Tobor, M. y Baath, E. (2004) Metal toxicity affects fungal and bacterial activities in soil differently. Appl Environ Microbiol 70: 2966-2973.

Rajendran, P., Muthukrishnan, J. y Gunasekaran, P. (2003). Microbes in heavy metal remediation. Indian. J. Exp. Biol. 41:935-944.

Rascio, N. y Navari-Izzo, F. (2011). Heavy metal hyperaccumulating plants: How and why do they do it?. And what makes them so interesting? Plant Sci. 180:169-181.

Raspanti, E., Cacciola, S., Gotor, C., Romero, L. y García, I. (2009). Implications of cysteine metabolism in the heavy metal response in Trichoderma harzianum and in three Fusarium species. Chemosphere 76:48-54.

Rauser, W. (1999). Structure and function of metal chelator produced by post: the case for organic acids, aminoacids, phytin ad metallothioneineins. Cell Biochem Biophys. 31:19-48.

Roane, T y Pepper I. (2000). Microorganisms and metal pollution, Environmental Microbiology edited by Maier R, Pepper I \& Gerba C . Academic press. London New York.

Rudas G., Espitia J., Mena J., Pardo L., Fierro J., Olivero J., C., Guerrero K., Caballero K., Vargas F., Negrete R. (2013). Minería en Colombia: Institucionalidad, Territorio, Paradojas y Conflictos. Contraloría General de la República. 
Rulkens, W., Tichy, R., Grotenhuis, J. (1998). Remediation of polluted soil and sediments: perspectives and failures. Wat. Sci. Tech. 37(8) 27-35.

Saadoun, I. y Al-Ghzawi Z. (2005). Bioremediation of petroleum contamination. Biorem Aquat Terr Ecosyst. 173-212.

Saleth, H. (2012). Water hyacinth for phytoremediation of radioactive waste simulate contaminated with cesium and cobalt radionuclides. Nucl. Eng. Des. 242: 425-432.

Samantaray, S., Rout, G. y Das, P. (2001). Induction, selection and characterization of $\mathrm{Cr}$ and Ni tolerant cell lines of Echinochloa colona (L). Link in vitro. J. Plant. physiol. 158: 1281-1290.

Sambandan, K., Kannan, K., y Raman, N. (1992). Distribution of vesicular-arbuscular mycorrhizal fungi in heavy metal polluted soils of Tamil Nadu, India. J. Environ. Biol. 13:159-167.

Samuelson, P., Wernerus, H., Svedberg, M y Stahl, S. (2000). Sthaphylococcal surface display of metal binding polyhistydiyl peptides. Appl Environ Microbiol 66:1092-1096.

Sanyal, A., Rautaray, D., Bansal, V., Ahmad, A y Sastry, M. (2005). Heavy metal remediation by a fungus as a means of production of lead and cadmium carbonate crystals. Langmuir 21(16): 7220-7224.

Singh, O., Labana, V., Pandey, G., Budhiraja, R. y Jain, R. (2003). Phytoremediation: an overview of metallic ion decontamination from soil. Appl. Microbiol. Biotech. 61:405-412.

Sinha, A., Pant, K. y Khare, S. (2012). Mercury bioremediation by mercury accumulating Enterobacter sp cells and its alginate immovilized application. Biodegradation 23(1):25-34.

Srivastava, R., Deng, Y. y Howell, S. (2014). Stress sensing in plants by an ER stress sensor/transducer, bZIP28. J. Plant. Sci. 5:59.

Solisio, C., Lodi, A., Soletto, D., Converti, A. (2007). Cadmium biosorption on Spirulina platensis biomass. Bioresource Technol. 99: 5933-5937.

Sood, A., Uniyal, P., Prasanna, R. y Ahluwalia, A. (2012). Phytoremediation potential of aquatic macrophyte, Azolla. AMBIO: J. Human Environ. 41(2):122-137.

Soto, C., Gutiérrez, S., Rey-León, A. y González, E. (2010) Biotransformación de metales pesados presentes en lodos ribereños de los ríos Bogotá y Tunjuelo. NOVA 8(14):195-205.

Swain, G., Adhikari, P. y Mohanty, P. (2014). Phytoremediation of Copper and Cadmium from Water Using Water Hyacinth, Eichhornia crassipes. Int. J. Agric. Sci. Technol. 2(1): 1-7.

Üçüncii, E., Tunca, E., Fikirdeşici, S., Özkan, D y Altindağ, (2013). Phytoremediation of $\mathrm{Cu}, \mathrm{Cr}$ and $\mathrm{Pb}$ Mixtures by Lemna minor. Bull Environ Contam Toxicol (2013) 91:600-604. 
Van Assche, F y Chysters, H. (1990). Effect of metals on enzyme activity in plants. Plant. Cell. Environ. 13:195-206.

Waalkes, M. (2003). Cadmium carcinogenesis. Mutat. Res.-Fund. Mol. Mech. Mutagen 533 (1-2), 107120.

Wang, P., Mori, T., Komori, K., Sasatsu, K., Toda, K. y Ohtake, H. (1989). Isolation and characterization of and Enterobacter cloacae strains that reduces hexavalent chromium under anaerobic conditions. App. Environ. Microbiol 55:1665-1669.

Weerasinghe, A. Aruyawnasa, S. y Weerasooriya, R. (2008). Phytoremediation potential of Ipomea aquatica for $\mathrm{Cr}$ (IV) mitigation. Chemosphere 70: 521-524.

Whiting, S., Leake, J., Mc. Grath, S. y Braker, A. (2000). Positive responses to Zn and Cd by roots of Zn and Cd hiperaccumulator Thlaspi caerulescens. New Phytol 145;199-210.

Wiatrowski, H., Ward, P. y Barkay, T. (2006) Novel reduction of mercury (II) by mercury-sensitive dissimilatory metal reducing bacteria. Environ Sci Technol 40:6690-6696.

Wu, G., Kang, H., Zhang, X., Shao, H., Chu, L. y Chengjiang, R. (2010). A critical review on the bio-removal of hazardous heavy metal from contaminated soil: Issues, progress, eco-environmental concerns and opportunities. J. Hazard. Material 174: 1-8.

Zeguers, I., Martins, J., Willem, R., Wyns, L. y Messens, J. (2001) Arsenate reductasa from S. aureus plasmid pI258 is a phosphatase drafted for redox duty. Nat. Struct. Biol 8:843-847.

Zhu, Y., Zayed, A., Qian, J., De Souza, M. y Terry, N. (1999). Phytoremediation of trace elements by wetland plants: II. Water Hyacinth. J. Environ. Qual. 28:339-344.

Zilli, J., Rumjanek, N., Xabier, G., Countinho, H y Neves, M. (2003). Diversidade microbiana como indicador de qualidade do solo. Cad Cienc Tecnol 20(3):391-411.

Zolgharnein, H., Karami, K., Assadi, M. y Sohrab A. (2010). Investigation of heavy metals biosorption on Pseudomonas aeruginosa strain MCCB 102 isolated from the Persian gulf. Asian J. Biotechnol 2:99109. 


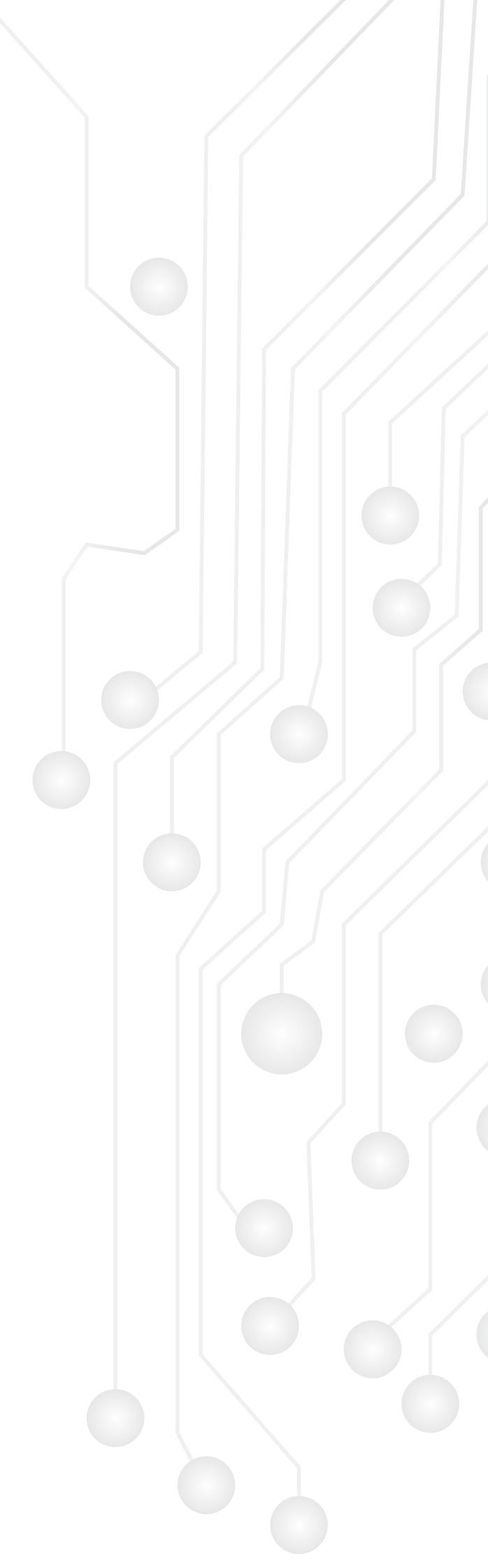

